\title{
The Visibility of Survivors and Experience as Expertise
}

This chapter examines the multi-layered processes through which adults who had been abused in childhood-survivors-began to discuss their experiences of abuse in public, often for the first time, through published letters, autobiography, newspaper interviews, and testimonies offered to academia and social policy. These spaces were shaped by and reshaped the narration of individual experiences and emotions, entwining personal processes of thinking and remembering with the changing interests of publishing houses, newspaper editors, and researchers. The chapter argues that public and political attention shifted to the long-term effects of child abuse for the first time only in the 1980s, and particularly from the 1990s, decades after attention had been paid to the experiences and emotions of children and parents. It took time for survivors to come forward, and for public and policy attention to consider the long-term effects of abuse on children. While the chapter uses the word 'survivor' as shorthand, echoing contemporary accounts and the activism of multiple voluntary groups, survivor testimonies-influential in social policy and media interviews from the 1990s and 2000s-have also demonstrated the complexity and range of lived experiences of abuse.

As attention was turned towards survivor experiences and emotions, several processes traced through this book solidified at the turn of the twenty-first century. Notably, experiential knowledge became a key

(C) The Author(s) 2018

J. Crane, Child Protection in England, 1960-2000, Palgrave Studies in the History of Childhood, https://doi.org/10.1007/978-3-319-94718-1_7 
resource for framing - and for criticising-political and media analysis. Continuing a process traced throughout this book, consultation with voluntary groups remained the key mechanism to access survivor views and, to a new extent, representative groups grew and consciously entwined experiential and professional expertise. As we saw in the previous chapter, under New Labour individual voluntary leaders found new opportunities to influence public inquiries-although survivor spokespeople remained critical of state legislation and services. These spokespeople operated at a juncture: at times reliant on state-funding, often lobbying for legislative change, but also seeking to work productively with social services, police, and law.

Relationships between survivor representatives and specific journalists cross-cut this policy work, and survivors used media interest to express their viewpoints and to criticise child protection practice. This chapter hence demonstrates that the expertise of experience and emotion had become significant by the year 2000 and that, in this context, survivors themselves were able to play a significant role in reshaping policy and media debate about child protection. This new role, primarily assumed through voluntary groups, intervened in long-standing relationships between policy, media, and publics, and raised questions, which would become key in the twenty-first century, about whose experiences and emotions were being represented on the public stage.

\section{CONFessional Cultures?}

From the mid-1960s, amidst renewed interest in child protection, social policy and medical texts made only occasional mention of the potential long-term effects of childhood abuse. Adults who were abused in childhood may have been speaking privately with agony aunts, counsellors, psychologists, and to one another before this decade, but their accounts were not yet heard publicly. Survivor accounts indeed were notably absent from broader 'confessional cultures' and 'cultures of self-expression' which, Deborah Cohen and Martin Francis have argued, emerged from the 1930s to the 1970s, or from the late 1950s and early 1960s. ${ }^{1}$ Without open discussions about child protection at this time, survivors could not yet discuss their personal experiences or emotions on the public stage.

From the 1980s, however, early accounts about the long-term effects of childhood violence began to surface. Developing psychological research about trauma was also important in this moment, and the category of 
post-traumatic stress disorder was first included in the 1980 edition of the Diagnostic and Statistical Manual of Mental Disorders. ${ }^{2}$ In this context, psychologists discussed the 'long-term effects' of guilt, trauma, betrayal, and secrecy for children, and the 'psychological scars' that may 'remain for a lifetime' following childhood abuse. ${ }^{3}$ Social surveys - conducted by academics, popular magazines, and the voluntary sector-likewise were looking to uncover the long-term effects of abuse. A survey in Woman magazine in 1983 found that of 15,000 respondents, one-twelfth had suffered sexual abuse within their family. ${ }^{4}$

Social policy documents likewise began from the 1980s to consider this issue. The report of the public inquiry into the Cleveland case, published in 1987, included one paragraph mentioning that the Member of Parliament Frank Cook had provided information from three brothers who had revealed after many years that their father had sexually abused them as children. ${ }^{5}$ The report did not present further details, simply writing that this did not come within its remit. Nonetheless, it emphasised that this suggested broader and long-term problems, that: perpetrators may remain in communities; abused children may require counselling in their futures; and authorities may face 'insuperable difficulties' confronting retrospective accusations of abuse. ${ }^{6}$ While not addressing these issues at length, the report stated that this was an area 'we feel should be recognised and consideration given to it'?

To an extent then, psychological, sociological, and policy researchers working in child protection were increasingly confronting the long-term effects of childhood abuse through the 1980s. This analysis signalled an important shift in terms of thinking about abuse over the life course, and in terms of its long-term effects-points notably absent from earlier debates which focused solely on the child in their childhood, rather than the child as a long-term, reflexive, living, and ageing subject. Survivors themselves in part drove this increased focus on their experiences. A range of charities - the NSPCC, ChildLine, Kidscape, Samaritans, Phoenix Survivors, and Relate-all testified that adults who were abused in childhood started to contact them, seeking help, in the 1980s and 1990s. ${ }^{8}$ Survivors later testifying to select committee inquiries in the early 2000 s emphasised that they had been 'too scared' to come forward as children, and that they had needed time to 'feel strong enough to give evidence'.?

These personal journeys of reflection occurred at the same time as new spaces opened up for children to disclose their experiences in the 1970s and 1980s, and alongside broader psychological interest in trauma. While survivors played a significant role in this process by coming forward 
in the 1980s and 1990s, professions also mediated the ways in which their experiences would be heard, disseminated, and used. The complex interactions between survivors-calling for assistance-and media, the voluntary sector, and policy may be analysed through a series of case studies: the work of agony aunts, autobiographies, and the NSPCC's Childhood Matters project.

\section{Agony Aunts}

Agony aunts are an important case study, demonstrating how the public narration of private experiences by survivors was mediated by the norms, cultures, and agendas of national institutions-newspapers - and by 'new experts' in confessional culture. Agony aunts turned to focus on child sexual abuse as a topic from the early 1990s, initially thinking about children but, later, shifting their focus towards adults. In these years, agony aunts told newspapers that they received a 'distressingly large' number of letters on child abuse - with indeed Deidre Sanders, agony aunt for the Sun, stating that one in five of her letters discussed this topic. ${ }^{10}$ Accordingly, Sanders began to respond to many such letters in her column, publishing almost 400 letters about abuse and violence between 1998 and August 2015. Suggesting a further increase in openness about this area over the early twenty-first century, over half of these letters were published between January 2013 and August 2015. ${ }^{11}$

Agony aunts played a significant role in publicly disseminating lengthy individual and qualitative accounts, adding to the quantitative data collected by social surveys and the private qualitative information recorded by psychologists and public inquiries. People's experiences were framed in emotional terms: letters to the Sun's 'Dear Deidre' page described life histories and, following this, testified that people felt 'so full of anger and hate' or 'frightened' about discussing their childhood abuse. ${ }^{12}$ Sanders emphasised that abuse may leave 'emotional scars' and could surface in later relationships. ${ }^{13}$ While the bylines chosen for these letters emphasised negative emotions-for example, 'Haunted by years of childhood abuse' and 'So hurt by evil abuser'-the letters' content also often reported therapeutic progress. In 2002, one young person of 26 wrote to the Sun to announce that, after Sanders had provided information and recommended counselling, they had 'moved on enormously' in their thinking. ${ }^{14}$ While agony aunts therefore provided important support, the selection, publication, and framing of public letters also 
demonstrated significant interest in this period in lived experiences and the power of emotion. Emotion was coded as a motivational force; encouraging people to write to newspapers, to bring their perpetrators to justice, or to reach out to others. However, emotion was also presented a barrier to action-described as stopping adults from having spoken out before, and as a hindrance to developing relationships or careers.

These letters were therefore not only a product of shifting openness in discussing child abuse, nor of increasing disclosures from survivors about their life experiences. The publication of these letters also reflected the shifting interests of newspaper editors-issues that they thought would sell papers - and the assumed interests of members of the public. In 1993, agony aunt Suzie Hayman of Woman's Own discussed public letters as a commercial entity, as well as a therapeutic forum, emphasising that newspapers 'put a lot of money' into providing 'an enormously expensive reader service', and that they 'can't justify that unless the column's entertaining'. ${ }^{15}$ While the agony aunt column was a 'service' to the public, the content of letters chosen for publication also revealed shifting ideas about what would 'entertain' newspaper readerships. Indeed, and reflecting different norms around discussing abuse, Independent agony aunt Virginia Ironside argued in 1993 that the 'very, very nervous broadsheets and posher papers' were later to offer agony aunt columns than tabloids, fearing initially that such columns may be 'tacky and silly'. ${ }^{16}$

Nonetheless, in curating and responding to these letters, agony aunts from tabloids and broadsheets alike emerged as a new type of visible and highly accessible expert in child protection. Agony aunts testified that they were often the first people who survivors shared their accounts with, and that many had previously 'kept the feelings bottled up inside themselves'. ${ }^{17}$ In becoming expert, agony aunts further blurred the boundaries between professional and personal forms of expertise. Continuing a shift towards professional reflexiveness, visible throughout this book, agony aunts discussed their own emotional responses to receiving these letters, discussing how they were 'really upsetting' and made them 'sad' and 'angry'. ${ }^{18}$ In addition, and extending the professional openness traced in Chaps. 5 and 6 through the 1980s, agony aunts also disclosed their own life stories, and indeed argued that personal histories of counselling, mental health, and family challenges, for example, provided key 'qualifications' with which to answer public letters. ${ }^{19}$ 
Tied in with their focus on experiential expertise as a resource, and with their own provision of expert help, agony aunts both replaced and challenged statutory services in child protection. Interviewing agony aunts in 1993, the Observer argued that letters were sent by people who had been ignored by teachers, doctors, and 'others in authority'.$^{20}$ Ironside testified that people often wrote to agony aunts 'because the experts have failed them'. ${ }^{21}$ Agony aunts acted politically and used this analysis of expertise to challenge broader social policies and social changes. While some agony aunts argued that 'resources are dwindling for social work', Philip Hodson, writing for News of the World, contended that child abuse had risen in response to parental employment and the divorce rate. ${ }^{22}$

Agony aunts therefore gleaned significant personal authority as individuals, and were able to challenge social and political change beyond child protection issues alone, but nonetheless with expertise based on their exposure to, and grasp of, public experiences and emotions. Recognising that public accounts were key to the construction of their expertise, agony aunts regularly deferred to self-help organisations, directing public inquiries to these groups, and also explicitly stating that many survivors wrote to their columns because others had. ${ }^{23}$ Through the emergence of agony aunts, therefore, the experiences and emotions of survivors became visible. The sharing of these experiences and emotions bolstered the expertise of survivors, but also constructed the media as a provider of therapeutic care, a voice for marginalised populations, and a key critic of state services.

\section{Autobiography}

Autobiographies, like letters to agony aunts, became an important medium through which to express and share experiences of childhood abuse from the 1970s, 1980s, and 1990s. Again, this medium reflected both increasing willingness from members of the public to discuss their childhood experiences openly, but also a new commercial appetite-in this case from the publishing industry-for sharing experiences and emotions. The confessional memoir has a long history. Deborah Cohen has shown that interwar memoirs were highly candid, capitalising on a primarily female market which 'liked to read about family skeletons'. ${ }^{24}$ In the late twentieth century, new forms of the confessional memoir emerged, linked in with developments in second-wave feminism, the interests of commercial publishers, and increasing social explicitness about the internal mechanisms of family life. 
From the 1970s, second-wave feminists offered new accounts of childhood abuse which looked to mobilise descriptions of experiences and emotions to lobby for political change, and to draw together thinking about violence against women and children. Demonstrative of the growing production of such work by voluntary groups, writing from the London Rape Crisis Centre in 1981, one Spare Rib article emphasised that adult women who faced sexual abuse may experience vivid flashbacks, leaving them 'numb, depressed or acutely anxious', and experiencing feelings of blame, betrayal, humiliation, outrage, anger, and upset. ${ }^{25}$ Feminist authors also produced memoirs and autobiographies describing their own experiences and those of others. Louise Armstrong's Kiss Daddy Goodnight (1978) was significant in this regard. Drawing on testimony from 183 women, recruited through adverts and peer networks, the book contained letters about incest written by women of 'every class, every family structure', charting experiences of fear and trauma, confusion and denial. ${ }^{26}$ The book's back cover emphasised that Armstrong had written this text 'through the words of the victims themselves', breaking a 'conspiracy of silence'. ${ }^{27}$ Reflecting in 2008, an obituary of Armstrong offered a similar perspective, arguing that her work had given many survivors 'the courage to speak out'. ${ }^{28}$

Within Armstrong's book, descriptions of emotion were central to women's accounts of their experiences, and contributors expressed hurt, guilt, fear, disbelief, denial, anguish, and rage. ${ }^{29}$ One contributor questioned why she had never received help, given the transparency of her 'obvious emotional trauma', clear to 'anybody who had an IQ of more than one point above a ripe cucumber' ${ }^{30}$ The text therefore framed descriptions of experience and emotion as challenging existing professional services, and as challenging structural systems of patriarchy and power. In 2003, Armstrong argued that since 1978, and the publication of her book, 'experts' had sought to appropriate the experiences of survivors and of women and to 'dismiss feminist analysis as biased, political, unprofessional'. ${ }^{31}$ Her book and subsequent works, therefore, positioned experiential expertise as authoritative, continuing women's efforts to present their own experiences, and those of others, publicly.

From the 1990s and 2000s, decades after the development of feminist memoirs about child abuse and incest, another distinctive form of child protection autobiography was popularised. ${ }^{32}$ Informally titled 'misery lit', Victoria Bates has argued that such works were framed by a 
feminist-psychoanalytic model and centred around a single traumatised female, her traumatic memories, and a traumatic event. ${ }^{33}$ These works, providing explicit accounts of childhood trauma, were written by men as well as women: the books A Child Called It (1995), The Lost Boy (1997), and A Man Named Dave (2000), all written by Dave Pelzer, were important in this genre. ${ }^{34}$ Like earlier feminist accounts, these works brought narratives about the experiences and emotions involved in recalling historic abuse to wider audiences. Pelzer's first book, for example, described how his 'will to somehow survive' continued despite significant abuse by his mother, including physical violence, neglect, enforced labour, and 'using food as her weapon'. ${ }^{35}$

A Child Called It included graphic descriptions of Pelzer's childhood abuse, recalling his sensory environment and emotions. For example, in one passage Pelzer described how his mother burnt him on a hot stove, and he described the feeling of his skin-which 'seemed to explode from the heat' - and the smell of the 'scorched hairs from my burnt arm'. ${ }^{36}$ Significantly, and demonstrative of public interest in such graphic accounts, 'misery lit' became an incredibly popular genre. In 2006, 11 of the top 100 bestselling paperbacks were memoirs about surviving abuse. Newspapers and publishers reported that supermarkets were a key space in which these books were sold, and that their purchasers were 80-90 per cent female. ${ }^{37}$ The popularity of 'misery lit' declined from 2008 , in part as journalists challenged the veracity of some accounts-including those offered by Pelzer - but also shaped by a changing economic climate. ${ }^{38}$ The journalistic concern about the 'truth' of these accounts reflected a growing mode of investigative research, but also showed that long-standing sites of expertise would police, criticise, and analyse survivors' expressions of experience and emotion, once made public.

In part, there was tension between the genres of the 1970s and 1990s autobiographies. The trauma scholar Anne Rothe has argued that while Armstrong's book was 'part of her feminist activism', and a call for cultural and political change, 'misery lit' sought 'to sell the pain of others as entertainment'. ${ }^{39}$ Contemporary journalists echoed this argument: an article in the New York Times about Pelzer was titled 'Dysfunction For Dollars', while the Observer wrote about 'Child abuse as entertainment', and the Independent described 'A million-dollar industry called Dave'. ${ }^{40}$ Nonetheless, the publication, popularity, and dissemination of all of these texts marked a key shift in late twentieth-century British society. Survivors were able to share their own experiences in public, in their own terms, 
often for the first time, and these accounts were commercially, publicly, and politically significant. Survivor accounts provided in feminist and 'misery lit' texts alike were not solely framed around 'misery', 'cruelty', and 'despair', but also in terms of 'hope', 'resilience', 'survival', and 'triumph'. ${ }^{41}$ Enabling survivors to provide their own accounts led to complex representations of emotion over the life course. These works presented the confrontation of experience and emotion as a liberating process, and were supported by concurrent accounts from survivors in newspapers about the entwined and long-term physical, emotional, and mental effects of childhood abuse. ${ }^{42}$

The ways in which survivor autobiographies were promoted and discussed in this late twentieth-century moment were distinct to the British context. While journalists in British newspapers criticised the idea that suffering had become entertainment, national publishers also sought to frame these books carefully, in comparison to how the same books were packaged and marketed in America. Making this point in 1988, an article in Feminist Review argued that the American marketing of Kiss Daddy Goodnight involved 'disgusting, almost titillating hype', presenting the book as 'A shocking, challenging expose of our ultimate sexual taboo!'43 In 2001, the Observer reported that most British publishers had initially rejected Pelzer's book, even though it had been on the New York Times bestseller list for three years. The newspaper reported a 'consensus' among British publishers that this type of descriptive account 'wouldn't work here'. ${ }^{44}$ When Pelzer's first book was published in Britain, the Observer stated, publishers replaced its 'garish' packaging with a 'classy-looking' cover. ${ }^{45}$ British audiences, like American ones, were interested to read these graphic recollections of childhood experience and emotion, but they were marketed in Britain in more careful, discrete, and private terms.

Examination of autobiographies relating to child abuse thus demonstrates another new space in which survivor experiences and emotions were shared from the late twentieth century. This space was governed by survivors themselves - sharing positive as well as negative accounts-but also by the interests of commercial publishers and members of the public, and by overarching cultural frameworks of trauma and emotion. Discussing childhood abuse was constructed variously as therapeutic, politically powerful, and as public entertainment. Yet discussions were also modified by distinctly British assumptions about when and how private family experiences should be shared and made public, and policed by concerns about whether descriptions of personal experience were 'authentic' or 'true'. 


\section{CHILDHOOD MATTERS}

In addition to growing focus from newspapers and publishing houses, academic and charitable interest in the long-term effects of childhood abuse was also developing from the mid-1990s. The National Commission of Inquiry into the Prevention of Child Abuse was notable in this context, established in 1994 by the NSPCC to consider the 'different ways in which children are harmed, how this can best be prevented, and to make recommendations for developing a national strategy for reducing the incidence of child abuse'. ${ }^{46}$ The Commission members hailed from a range of professions and backgrounds. The Chair was former lawyer and Labour life peer Lord Williams of Mostyn, while other members were drawn from social work, academia, paediatrics, and Parliament. The NSPCC also appointed the chief executive of Channel Four, Michael Grade, and Sun agony aunt, Deidre Sanders, with the hope of gaining 'more coverage in the popular press and on television'-again indicative of growing public interest in this topic, and increased political recognition of the significance of media support. ${ }^{47}$

The Commission did not directly appoint individuals personally affected by abuse, though it did seek out their written contributions, as well as those from educationalists, clinicians, lawyers, researchers, and journalists. The Commission collected 10,000 testimonies in total. ${ }^{48}$ Significantly, one chapter of the final report's 'Background Papers', co-written by the sociologists Corinne Wattam and Claire Woodward, focused on learning about prevention from those personally affected by abuse. ${ }^{49}$ Following a parallel system to Armstrong, Wattam and Woodward placed adverts in agony aunt pages looking for the 'experiences' of 'victims of abuse', and received 1121 letters. ${ }^{50}$ The majority of these (721) told the author's life story; 130 responded directly to the Commission's terms of reference; and the remainder were written by concerned relatives, friends, and professionals. ${ }^{51}$ People who identified as female wrote 88 per cent of life-story letters. This gender disparity-in addition to reflecting the market for 'misery lit'-was also replicated in the responses to surveys conducted in the 2010s, suggesting an extent to which women felt more comfortable, or expected, to disclose, read about, and discuss historic abuse. ${ }^{52}$

In analysing these letters, Wattam and Woodward aimed to assess the common causes and types of child abuse, the ages at which abuse typically started, and the person believed responsible. Wattam and Woodward also analysed whether, when, and how the authors had reported abuse, and the 
strategies for recovery and prevention which they had found helpful. ${ }^{53}$ This represented a focus, again present in earlier sociological and policy work, in using survivor experience to draw 'lessons' for future practice. The key lessons drawn echoed the points made by agony aunts. Many letters received pinpointed a culture of denial within which abused children and surviving adults were encouraged to remain silent. Thirteen per cent of the 721 lifestory letters were written by authors who had never spoken about being abused before ${ }^{54}$ Authors suggested that the majority of Britons would rather pretend that child abuse did not exist than address its unpleasant realities. ${ }^{55}$ Within the life-story category, only 32 per cent of authors had told someone about their abuse as a child, and 29 per cent of these people had received a 'negative' reaction and been ignored, dismissed, or even punished. ${ }^{56}$

A suspicion of child protection professions and systems emerged in Wattam and Woodward's study. Respondents described the 'child abuse system' as a 'faceless group' which had treated them abusively, and made particular criticism of health, psychiatric, and social and legal services. ${ }^{57}$ Demonstrating an appetite for peer support, one respondent wrote that 'the last thing we need is someone who knows nothing apart from what they have read in books or through so-called training' ${ }^{58}$ Others argued that child protection professionals should have 'firsthand experience' or 'have been abused in childhood themselves'. ${ }^{59}$ A study published in 2002 also directly addressed this belief in peer support, and was written by Christine Walby, a member of this NSPCC Commission, Matthew Colton, a child welfare academic, and Maurice Vanstone, a lecturer in criminology. On carrying out detailed interviews with 24 individuals who were abused in residential homes, Walby, Colton, and Vanstone found that 'several subjects' of their interviews emphasised the importance of self-help groups, and that 'some felt that such groups offer the most effective form of help for survivors' ${ }^{60}$

As such, the National Commission of Inquiry into the Prevention of Child Abuse directly sought out and took seriously the experiences of adults who had been abused in childhood, foreshadowing later work in child welfare and criminology. ${ }^{61}$ While this type of consultation was becoming increasingly important in policy and academic analysis, it was not the central focus of the Commission's final report, Childhood Matters (1996). Rather, the report focused primarily on providing recommendations to prevent future abuse, notably encouraging: better cooperation between health, children's services, probation services, teachers, and voluntary groups; and the creation of mechanisms for community reporting. ${ }^{62}$ Discussing the project, Members of Parliament 
and journalists likewise focused on prevention, and often on the recommendations to instate a Minister for Children and to see children as individuals, not possessions. ${ }^{63}$

Discussion of the long-term experiences of survivors was nonetheless present in Childhood Matters, which argued that the contemporary legal system was sometimes 'as damaging as the original abuse itself'. ${ }^{64}$ Furthermore, covering the report, the Guardian reprinted a comment from Lord Williams that 'the voices of survivors ... were constantly in our minds' ${ }^{65}$ Bolstered by broader shifts in confessional culture, and by the recognition of the long-term effects of trauma, social policy and the voluntary sector-along with commercial agencies-were turning their attention to the experiences and emotions of survivors, for the first time, from the 1980s and particularly from the 1990s. Social policy-makers and researchers were also beginning, for the first time, to couch the significance of their work in terms of accessing experiential expertise.

Childhood Matters was important also in extending debates from the 1980s, analysed in Chaps. 5 and 6, which encouraged practitioners and researchers to reflect on and share their own emotions and experiences, particularly when analysing child protection. Again, this belief was later addressed directly in the research of Walby, Colton, and Vanstone. Testifying to the range of emotions which survivors themselves expressed, the researchers found that their survey respondents felt 'anger' and 'pain' but that they also described the 'dignity of survival'. ${ }^{66}$ Walby, Colton, and Vanstone argued that listening to these stories was 'humbling and traumatic', and that they were concerned about the impact which their own research and 'intrusion' was having on their interviewees. ${ }^{67}$

Turning their gaze to social work and police, Walby, Colton, and Vanstone also argued that 'emotional distancing' by professions could be received very negatively, and could leave survivors 'being defined as "other" and in a sense dehumanized'. ${ }^{68}$ Criticism of the legal system in this regard was echoed in 2002 by survivors providing evidence to the Home Affairs select committee, one of whom argued that, 'my experiences were viewed as pieces of paper' when seeking redress. ${ }^{69}$ While another respondent to this committee argued that the Criminal Prosecution Service had done a 'good job', the entry of adult survivors into child protection debate nonetheless invited further professional reflection. ${ }^{70}$ 


\section{Collective Action}

Echoing the focus on community support in Childhood Matters, new voluntary and self-help groups emerged in the late-1990s and 2000s to support survivors in Britain, developing alongside parallel groups in America, Europe, and Australia. ${ }^{71}$ These groups sought to enable survivors themselves to provide narrative accounts of their experiences in collective terms, adding to representations collected and constructed by state, professional, and commercial organisations. In Britain, new voluntary organisations included national groups such as the National Association for People Abused in Childhood (NAPAC), One in Four UK, and Phoenix Survivors, and regional groups such as Survivors Swindon, Nottinghamshire's Survivors Helping Each other, and Norfolk's Surviving Together. By 2015 , there were at least 135 of these national and regional groups united under the umbrella organisation The Survivors Trust. ${ }^{72}$

The shape, aims, and membership of each of these groups varied markedly. Some groups had specific foci, such as the Male Survivors Trust, Childhood Incest Survivors, and Minister and Clergy Sexual Abuse Survivors. ${ }^{73}$ Regional groups were usually small and primarily constituted by weekly or fortnightly support meetings, although some created leaflets, newsletters, and helplines. Other groups also engaged in campaign work. For example, Phoenix Survivors organised several national campaigns and spoke to Members of Parliament and journalists to lobby for restrictions in where sexual offenders could live and work. ${ }^{74}$ Notably, Phoenix Survivors took a broad approach to the problems of survivors-for instance helping people to pay their bills - as the group argued that challenges to material living situations reflected and contributed to people's 'bleak emotional state[s]'. ${ }^{75}$

One key parallel across these disparate groups was that many were founded by adults who had themselves faced historic abuse, and who had struggled to access professional help. Phoenix Survivors was established by Shy Keenan in 2001, who wanted to use her experiences of physical and sexual abuse and neglect to help others. Keenan was joined in 2006 by Sara Payne, whose activism was discussed in Chap. 6, and the group's mandate was extended to also provide support for families of murdered children-indicative of how leaders governed and reshaped the priorities of voluntary groups. ${ }^{76}$ Peter Saunders founded NAPAC, one of the largest groups working in this area, in 1997. Saunders had come to reflect on his childhood experiences of abuse when he was in his late 30s, in the mid-1990s. ${ }^{77} \mathrm{He}$ had struggled to find 
support, telling newspapers that telling his family had 'torn' them apart and that he had tried to call ChildLine and the NSPCC to no avail. ${ }^{78}$

Following this, a second shared premise underlying many of these support groups was the idea that adults who had been affected by historic abuse may be able to help one another, more than professionals could; an idea echoed in the concurrent academic studies by Wattam, Woodward, Walby, Colton, and Vanstone. Discussing this explicitly with The Times in 1996, Saunders argued, 'The one thing that bastard gave me is an ability to empathise with victims of child abuse. ${ }^{79}$ Testifying to the Home Affairs select committee in 2002, another survivor argued that through institutional abuse, in particular, they had been 'linked' to other victims by the 'perversion' of one perpetrator. ${ }^{80}$

While the value of experiential expertise was thus promoted by survivors speaking to social policy, select committees, and newspapers, many leaders of survivor support groups themselves initially questioned its worth, or their own status as expert. When Keenan first began to receive requests for help, she reported that she had felt 'lost', not only because she did not have the time or the money to reply to all requests, but also because she doubted her 'authority' to do so, in comparison to those working in legal, police, social work, or medical fields. ${ }^{81}$ In further interviews and in their own academic publications, nonetheless, the leaders of Phoenix Survivors and NAPAC came to assert that their personal experiences had given them the expertise to become spokespeople and had developed their emotional expertise and empathy. ${ }^{82}$

This premise shaped the specific types of support typically offered by these groups: phone lines staffed by other adults affected by abuse; websites with fora to talk to others; and online spaces in which adults could creatively express their feelings about the past, for example through paintings, poetry, and prose. As well as suggesting a growing culture of selfexpression in late twentieth-century Britain, these spaces also reflected the argument of Joanna Bourke that the communication of pain has forged 'bonds of community' throughout time. ${ }^{83}$ Memories of childhood abuse had forged informal interpersonal and community bonds previously, but these bonds became publicly visible, and to an extent publicly powerful, from the 1990s. A sense of community between and within survivor communities was fostered not only through the description of pain but also by sharing positive experiences of joy, strength, and happiness. ${ }^{84}$ Again, voluntary organisations provided a means for survivors to rebuff and challenge professional categorisations of survivorship, and to present 
complexity. While challenging professional interests, this activism also represented a radical model whereby the long-term impacts of child abuse would be defined, analysed, and even managed through collective peer support, which could supplement, or if necessary bypass, statutory, community, or family provisions.

These groups continued a significant new mode of voluntary action emergent since the 1960s. Like other groups studied in this book, they bridged the 'new politics' of identity and New Social Movements and more long-standing forms of self-help and mutual aid. The groups represented experiential knowledge, but were also not lacking in professionalism nor formal organisation: NAPAC, for example, won grants from the Department of Health, Home Office, National Lottery, charitable trusts, and private companies, as well as through fundraising. ${ }^{85}$ NAPAC also appointed formal boards of trustees and worked 'professionally' by establishing new helplines and websites and, as the chapter later outlines, working with policy and media. This book has analysed numerous such small voluntary groups who emerged around child protection and who, similarly, bridged 'professional' and 'expert', 'support' and 'advocacy' roles. The history of late twentieth-century Britain is incomplete without examination of such organisations.

\section{SurVIVORS AS EXPERTS}

While policy-makers had consulted certain types of patient and serviceuser from the 1960s, it was only in the late 1990s that researchers began to acknowledge the long-term impact of childhood abuse and to consult survivors, with experience of abuse, as expert. ${ }^{86}$ The potential mental health consequences of childhood abuse were first recognised by the state in the Mental Health National Service Framework (1999), the Women's Mental Health Strategy: Into the Mainstream (2002), and the Social Exclusion Unit Report on Mental Health and Social Exclusion (2004). ${ }^{87}$ In a related shift, the National Suicide Prevention Strategy of 2001 included an explicit objective 'to promote the mental health of victims and survivors of abuse, including child sexual abuse'. ${ }^{88}$

By the early-to-mid-2000s, policy-makers began to consult survivors, often in terms of soliciting or reading select committee evidence about their experiences and emotions, as collated by voluntary organisations. ${ }^{89} \mathrm{~A}$ range of models of consultation, all of which became important, were 
apparent in the Victims of Violence and Abuse Prevention Programme (VVAPP). The programme was established in 2005 by the Department of Health, the National Institute for Mental Health in England, and the Home Office. It aimed to consider the nature, extent, and effects of child sexual abuse, domestic violence, sexual assault, sexual exploitation, stalking, sexual harassment, forced marriage, female genital mutilation, and 'honour crimes'.$^{90}$ This broad approach to multiple issues demonstrated that, to an extent, social policy-makers were beginning to assess different types of violence in tandem in this period, following the late twentiethcentury contexts of the 1960s, 1970s, and 1980s in which child abuse and domestic violence were often approached separately.

The first stage of the VVAPP was to gather evidence and six teams consisting of professionals, academics, and voluntary organisations were established. ${ }^{91}$ One of these teams aimed to consider adult survivors of childhood sexual abuse. ${ }^{92}$ Twenty-one 'expert advisors' composed this group, including academics, police, mental health specialists, clinicians, and representatives from the Home Office. Also included were seven members of voluntary organisations representing NAPAC, the Women's Therapy Centre, Rape Crisis, First Person Plural, and The Survivors Trust. ${ }^{93}$ Suggestive that credence was paid to the experiential knowledge of survivors, Gillian Finch, the chair of The Survivors Trust, co-chaired this expert group alongside a Consultant Nurse on Sexual Abuse, Chris Holley. ${ }^{94}$ The expert groups established the aims and scope of the VVAPP, which ultimately produced several outputs: mapping the common pathways from childhood victimisation to subsequent re-victimisation and the health and mental health of adults, producing a directory of the 180 voluntary organisations providing counselling for victims, and creating a Delphi method consultation. ${ }^{95}$

The Delphi consultation was significant because it not only demonstrated an appetite to consult with survivors as experts but also a social policy desire to find singular policy 'solutions' from a diverse and complex group. The consultation gave questionnaires to 285 'experts', including representatives from medicine, law, policy, children's charities, and survivor groups. The questionnaires sought out opinions about the existing provision of therapeutic services for child, adolescent, and adult victims, survivors, and perpetrators of abuse. ${ }^{96}$ Responses were drawn through several rounds, whereby the survey was revised and redistributed after each round looking to uncover common responses. Of the 285 experts consulted, 123 responded to questions about adult survivors of childhood sexual abuse. ${ }^{97}$ In the relevant section, the experts were asked about the 
'most important principles and core beliefs' to inform work with 'victims/survivors', the most effective interventions, how to manage safety and risk, how to train people, prevention, and improving outcomes. ${ }^{98}$ While it is not clear how many survivors were consulted, a fixed question on the survey did ask those with 'expertise from personal experience' to explain what strategies had helped them to recover from violence and abuse. ${ }^{99}$

The final reports produced by the VVAPP documented several conclusions relevant to the care of adults abused as children. Analysis of the Delphi consultation found strong agreement that no 'single therapeutic approach' would be effective for all survivors - indicating that there was no simple, singular policy response. ${ }^{100}$ Participants agreed that any measures taken from the programme should be 'needs-led and victim/survivor centred', with all involved parties thinking carefully about survivor experiences, and giving survivors 'control' and 'choice'. ${ }^{101}$ While experts agreed on these broad principles, they disagreed about the efficacy of specific forms of therapy for survivors (namely regression, hypnotherapy, and inner child techniques) and also over whether therapy should be offered on an 'open-ended basis' or not. ${ }^{102}$ Experts also disagreed about whether those providing therapy needed qualifications and training, demonstrating that a level of professional suspicion remained about the value of peer support. ${ }^{103}$

The production, conclusions, and dissemination of the VVAPP demonstrated several key points about the ways in which survivors' experiences and emotions were becoming expertise in the 2000s. Notably, this project's survey consulted people with experiences of childhood abuse at the same time and in the same ways as those with professional experiences in law, social work, and medicine. This focus on experiential expertise was also highly visible in later analysis and framing of the programme and its results. In a subsequent book describing the VVAPP, the programme's director Catherine Itzin referred to the importance of consulting 'experts by both experience and profession'. ${ }^{104}$ At the press release for this programme in November 2006, the Minister of State for Public Health, Caroline Flint, stated that the VVAPP was 'essentially informed by the strong voice of victims and survivors, of all ages and from all backgrounds'. ${ }^{105}$

Significantly, leaders of voluntary organisations would mediate, represent, and interpret the 'strong voice' of survivors. Indeed, one summary report produced by the VVAPP stated that the voluntary sector 'represents 
the interests - and the voice - of victims and survivors'. ${ }^{106}$ Small voluntary groups had also played a significant role in representing the experiences and emotions of children and parents, as seen throughout this book. However, by the 1990s and 2000s, new spaces were also opening up for such small groups to yield significant influence over social policy and research. While the NSPCC's National Commission of Inquiry into the Prevention of Child Abuse, held in 1994, had invited survivors to write letters to its researchers, the VVAPP also appointed survivors, found through voluntary organisations, on to its advisory structures. One VVAPP publication released in 2006 even argued that 'survivor organisations' should become a key component in a broader system of multiagency co-operation, working as service providers alongside statutory services - a position in tension with survivor critique of such agencies. ${ }^{107}$

To an extent therefore, survivors had further opportunities to contribute to policy construction in the 1990s and 2000s, and spokespeople couched the significance of policy work in terms of accessing survivor experience. This marked a significant transition from the 1970s and 1980s, when the long-term effects of child abuse were rarely the focus of political inquiry, and in part reflected the work of survivors to represent their own experiences and emotions in autobiography, newspapers, and through collective action. Nonetheless, significant limitations remained in the extent to which survivors were able to influence social policy. ${ }^{108}$ Research by criminologists and by the parent representative Sara Payne emphasised that there was a significant 'implementation gap' between the rhetoric about victim and survivor support and the help provided. ${ }^{109}$

Further, voluntary survivor groups continued to struggle to gain financial support from successive governments, and statutory services were often the key beneficiaries of new financial commitments in victim support. ${ }^{110}$ Survivor representatives and groups also had to continue to assert their rights to be heard, and to justify the significance of experiential expertise. Saunders, the founder of NAPAC, stated in 2013 that his organisation was only represented during Operation Yewtree, looking into the sexual offences of Jimmy Savile, after a journalist asked why survivors themselves were absent from debate. ${ }^{111}$ Therefore, through voluntary groups, survivors found new pathways to share their experiences with policy-makers. Nonetheless, they were not always successful in disrupting existing processes of policy-construction, nor in making their experiences and emotions influential. 


\section{Role OF THE MEDIA}

Newspaper and televisual interest played a significant role in bringing public and political attention towards survivor experience and emotion, often through partnership between specific individuals in the media and leaders of voluntary organisations. Survivors guided these partnerships, but broader media tropes, interests, and agendas also shaped the narration of experience. One regular arena for survivor visibility and influence was in terms of, from the 2000s, leaders of voluntary groups offering expert comment on prevailing news stories, for example commenting on the appointments of new Ministers for Children, the issue of smacking as punishment, and the sentencing of sexual offences. ${ }^{112}$ Published letters and quotations by voluntary leaders were printed and placed alongside those written by politicians and the leaders of large children's charities, demonstrating the authority of survivor groups. ${ }^{113}$

Survivor representatives often used this media space to make significant critiques of policy and practice. For example, Saunders wrote to the London Evening Standard that the appointment of Margaret Hodge as the first Minister for Children was a 'bad appointment' and that 'jaws dropped', because of the cases of sexual abuse in local care homes while she had been the leader of Islington council between 1982 and 1992. ${ }^{114}$ Saunders emphasised that his critique represented the emotions and experiences of a broader community, arguing that this appointment had left survivors 'feeling disillusioned and saddened'. ${ }^{115}$ Saunders' role in representing survivor experience continued in coverage from 2005, when the European Court of Human Rights awarded damage payments to a convicted paedophile, because of delays in setting his trial date. This case accrued much tabloid interest, and the Daily Mirror, Daily Mail, and Daily Express all quoted Saunders, who told the Mail that he felt 'bewilderment' while survivors would experience 'pain' and 'heartbreak'. ${ }^{116}$

In addition to responding to political, legislative, and social changes, survivor organisations also drove newspaper agendas, particularly through their appointment of celebrity patrons who, by sharing their own experiences, directed journalistic attention towards the lived experiences of child abuse and the fundraising efforts of voluntary groups. NAPAC, for example, appointed celebrity chef Antony Worrall Thompson and model Jerry Hall as patrons. Both spoke out about their childhood experiences for the 
charity. Hall discussed how her father 'had a lot of rages' and was 'quite violent', meaning that she knew 'the trauma of being a child and living in fear'. ${ }^{117}$ Hall's statement, made while relaunching the NAPAC's helpline in 2006, received coverage in the London Evening Standard, the Sun, and the Express, leading Third Sector magazine to comment that 'the right celebrity with the right story can put a small charity on the front pages'. ${ }^{118}$

Survivor representatives also worked with television-for example Shy Keenan, of Phoenix Survivors, and Colm O'Gorman, of the charity One in Four, both made documentaries in partnership with the producer Sarah MacDonald, which aired on the BBC. These documentaries made the experiences and emotions of these voluntary leaders their primary subject, extending interest in the ability of such leaders to channel and represent broader communities of survivors. Keenan's programme was a sixtyminute Newsnight documentary, A Family Affair, which aired in November 2000. This documentary discussed Keenan's childhood and adulthood experiences, and featured undercover footage she had taken of her stepfather, Stanley Claridge, confessing to having sexually assaulted her and her sister, and to having allowed his friends to do so also, on multiple occasions. ${ }^{119}$ While Keenan's childhood had been in the 1960s and 1970s, she sought to confront Claridge again in 2000, in her late-thirties, feeling that her own life was more established, and out of concern that her stepfather may again have access to children. ${ }^{120}$ Keenan approached O'Gorman, who helped her to approach the BBC. ${ }^{121}$ After A Family Affair was aired more of Claridge's victims came forward and the police launched 'Operation Phoenix'. On the basis of this, Claridge was sentenced to 15 years in prison at the age of $82 .{ }^{122}$

Keenan therefore exerted significant influence in contributing to the creation and shape of A Family Affair. Her persistence brought her case to the attention of the BBC, and she provided the crucial undercover footage. Keenan also shaped a critique of professional services which ran through this documentary and its subsequent news coverage. The programme itself discussed how perpetrators remained 'unchallenged by the authorities', and featured a reassessment of Keenan's childhood case files, which had barely mentioned Claridge. ${ }^{123}$ In subsequent newspaper coverage, Keenan positioned her work as empowering, stating that she would fight for victims when they could not fight for themselves. ${ }^{124}$ While Keenan was thus empowered in terms of using her experiences to shape this call for change, visions of vulnerability also framed media coverage. The documentary, for example, showed footage 
of Keenan being sick on the side of a motorway after her encounter with Claridge. ${ }^{125}$ Subsequent media interviews described both Keenan's 'incredible bravery' and her 'vulnerability'. ${ }^{126}$

Continuing this close focus on the experiences and emotions of survivors, guided both by media interests and by survivors themselves, O'Gorman worked again with the director of A Family Affair, Sarah MacDonald, to make the documentary Suing the Pope (2002). ${ }^{127}$ Suing the Pope followed O'Gorman as he returned to his birthplace, County Wexford in Ireland, to expose a Catholic Priest who had sexually abused him between the ages of 14 and 16, and to highlight the institutional failings that had enabled this abuse. The programme highlighted the institutional barriers for individuals coming forward about child abuse, with particular focus on the power and insularism of Catholicism in this small community. ${ }^{128}$ O'Gorman was significant in directing the focus and content of this documentary. He reported that this work had given him a sense that religious and community power dynamics had shifted significantly, with the Catholic Church becoming the 'subject' of investigation, rather than the 'masters' of it. ${ }^{129}$ In later years, other survivor organisations also framed media responses to clerical abuse, and NAPAC called for the Pope to review historic cases, make an apology, and talk directly to community representatives. ${ }^{130}$

While O'Gorman was highly important in shaping the content of Suing the Pope, and the representation of his experiences on the screen, community and public responses to this television programme could not be controlled. The response to Suing the Pope was, an updated version reported, primarily dominated by more victims coming forward and by an outpouring of public sympathy for those involved. A radio presenter in Wexford told the programme that they had 'people ringing in crying', and, notably, 'women in tears'. However, a minority response made threats of violence towards the programme's interviewees. ${ }^{131}$ One interviewee later reported that they had initially struggled to cope with community attention after the documentary aired. They reported feeling like 'a goldfish in a goldfish bowl' and facing severe depression, although they later developed a sense of 'serenity'. ${ }^{132}$

Thus, by the 2000s survivors were in part able to drive media narratives around child protection, and were hailed by media as 'renowned expert[s]'. ${ }^{133}$ The expertise of these individual survivor representatives derived from their personal experiences of abuse, but also from their ability to represent the emotions of broader communities of survivors. 
Newspapers published critical letters from survivor leaders, but also complimented those who were 'measured and articulate', suggesting the ways in which tacit norms of 'appropriateness' governed which survivors became representatives and how. ${ }^{134}$ Indeed, not all survivors were convinced by the value of media relationships. One anonymous survivor of institutional abuse, for example, in 2002 told the Home Affairs select committee that the media 'seems to paint survivors of child abuse as money grabbing liars'. ${ }^{135}$ This testimony showed that, for some, suspicion of 'authority' and statutory services also extended towards the media. Further, the statement portrayed the challenges for voluntary leaders hoping to represent all survivor opinion publicly.

An early reconstruction of the Independent Inquiry into Child Sexual Abuse, founded in 2014 to explore historic cases, further probed this challenge. In 2014, the Guardian reported that panel members believed Home Secretary Theresa May was giving disproportionate influence to 'a vocal minority instead of the majority of abuse survivors', and that a 'small number of individuals and survivor groups' were exercising undue influence, particularly through their work with 'social media and the press'. ${ }^{136}$ In the early twenty-first century, therefore, as survivor groups further developed and became empowered partners in forming media relationships, the role of specific groups and leaders also faced new critique. This critique raised questions of representativeness and inclusion, but was also in part a revived challenge to the power and authority of experiential and emotional expertise.

\section{Childhood ANd Survivorship}

A complex relationship emerged between the constructed rights and responsibilities of survivors and children. On the one hand, interest in the experiences and emotions of children-traced in Chaps. 3 and 4 of this book-had lain the groundwork for professions and policy to listen to, and care about, the experiences and emotions of survivors in later years. Certain channels that were established in the 1980s for children, such as ChildLine, were later used by adult survivors looking to seek help and to raise awareness of the long-term effects of abuse. At the same time, the accounts provided by survivors in the 1990s and 2000s also demonstrated the limitations to the shifts traced in Chaps. 3 and 4 . While there was increasing rhetoric from charities and social policy about 'listening to children' over these years, later survivor testimonies demonstrated that many 
were unable to report abuse in these decades, nor to discuss their experiences publicly.

In the 1990s and 2000s, policy researchers looking for participants often suggested that survivors would be driven by a desire to protect future children, or that they even owed these children a duty of care, as part of a related community. Many survivors echoed this sentiment. Replying to Woodward and Wattam, one adult wrote that while 'we can't undo what happened to us', 'we can do a lot more to protect future generations' ${ }^{137}$ Providing evidence to the Home Affairs select committee in 2002 , another survivor argued for the prosecution of all historic perpetrators, because they posed 'a threat to other innocent children'. ${ }^{138}$ Politicians echoed the idea that survivors discussed their experiences and emotions in order to help future children, and that these testimonies could be mobilised to prevent future cases. ${ }^{139}$

While concern for present and future children was a significant driver for participation in social policy, survivors did not only speak out seeking to protect present and future children. Survivors also at times discussed their experiences and emotions as part of an individual therapeutic process, and to encourage other adults to seek help. Further, voluntary survivor organisations also sought to shift the focus of social policy and academic research from children alone towards analysis of the lifelong effects of abuse and neglect-areas which had been overlooked from the 1960s. Testimonies collated and published by voluntary organisations provided space for survivors to discuss their childhood experiences and the ways in which they had processed these as adults. ${ }^{140}$ To an extent, survivor groups felt that they faced a more challenging task than children's charities in forcing publics to confront these issues, and that their cause was less 'fashionable' than that of the 'cosy, cuddly charities' which focused on children. ${ }^{141}$ This tension between self-protection and protecting future children was also felt by individuals: one contributor to Armstrong's collection, for example, grappling with her decision to leave her children, asked, 'what about my needs as a child? What about my needs?' 142

By presenting the long-term effects of violence, testimonies provided by adult survivors changed the public and political perceptions of children facing abuse, emphasising that surviving children may face long-term emotional, physical, and mental issues which would require significant support. Testimonies in this area called for a reconceptualisation of childhood-to be approached as a transient state and assessed as part of a 
broader process of lifelong development, rather than separated off from thinking about adulthood. In this way, survivor campaigning challenged the broader post-war fixation on segregating childhood by 'stage' or 'category', visible, for example, in the proliferation of new categories in childhood psychology and education. ${ }^{143}$ This focus on approaching childhood as a transient state echoed work by Kidscape, studied in Chap. 4, in providing specific but interlinked support for children in infancy, childhood, adolescence, and as adults. Notions of survivorship therefore, and the sharing of lived experiences and emotions by survivors, came to the fore significantly later than the testimonies of children, but also challenged understandings of childhood.

\section{Conclusion}

Decades after children's voices were sought out by charities, social policymakers, and media in the 1970s and 1980s, in the late 1990s, and particularly from the 2000s, adults who had been abused in childhood-survivorsbegan to be heard. Survivor representatives themselves in part drove the process through which these individuals were increasingly sought out, listened to, and portrayed. Survivors took the lead in describing their experiences and emotions anew in literature, to agony aunts, and in newspaper interviews. Voluntary organisations were significant in providing a forum through which survivors could access peer support and contribute to political and media lobbying, and new groups emerged which cross-cut categories of self-help, identity politics, and 'professional' non-governmental organisations. The process through which survivors became visible was also, however, shaped by the interests and influences of, for example, publishing houses, journalism, academia, and social policy. Self-expression was also governed and narrated through the broader analytical categories of 'victim' and 'survivor', though these classifications were challenged, as well as adopted and changed, by voluntary groups.

Through these multiple fora, public and political attention turned to the long-term effects of child abuse for the first time in the 1990s and 2000s. The experiences and emotions of survivors became forms of expertise, consciously mobilised by survivors and sought out by media and policy. By the late 1990s, survivor representatives sat on consultative panels of select committees, large charities, and public inquiries, and also-at times in conflict with these formal roles-criticised social policy, political appointments, and judicial decisions through television and print media. 
More than the parent organisations studied in Chap. 6, survivor groups became incorporated into a broad landscape of supportive statutory and voluntary services, and they provided significant levels of peer support by phone and through the new medium of the internet. Nonetheless, notable gaps in provision for survivor welfare remained, and the inclusion of survivor representatives in social policy was at times tokenistic, temporary, and not reflected in policy change.

This chapter-and this argument-raises a significant question: when experience and emotion developed as forms of expertise, whose experiences and emotions became powerful, and in which spaces, and why? Notably, women were the first and primary users of private spaces to discuss and disclose historic abuse: social surveys, agony aunt columns, and peer support phone lines. Both male and female survivor representatives became visible speaking publicly about their experiences through literature, public policy inquiries, and media. While the child was often addressed as genderless in the educational materials studied in Chap. 4, therefore, by the 1990s and 2000s the gender of survivors shaped how they responded to abuse on a personal level, but also whether this response was made in private or public spaces, and as a consumer, peer supporter, recipient of therapy, or prominent spokesperson. While experts by experience and emotion became prominent in the late twentieth century, researchers and policy-makers rarely made assessment of which demographic groups they were empoweringor disempowering, nor of the extent to which experiential experts were drawn from specific class, gender, ethnic, or age groups. The next chapter of this book, its conclusion, considers inclusion and diversity alongside other key issues for the future of child protection work, and discusses how looking to history can reframe present thinking.

\section{Notes}

1. Deborah Cohen, Family Secrets: The Things We Tried To Hide (London: Penguin, 2014), 75-76, 196; Martin Francis, 'Tears, Tantrums, and Bared Teeth: The Emotional Economy of Three Conservative Prime Ministers, 1951-1963', Journal of British Studies, 41 (2002): 354-387.

2. See on this: Paul Lerner, and Mark S. Micale, 'Trauma, Psychiatry, and History: A Conceptual and Historiographical Introduction' in Paul Lerner and Mark S. Micale (eds) Traumatic Pasts: History, Psychiatry, and Trauma in the Modern Age, 1870-1930 (Cambridge: Cambridge University Press, 2009), 1-27, Edgar Jones and Simon Wessley, 'A Paradigm Shift in the Conceptualization of for the future of psychiatric 
canon and practice', Journal of Anxiety Disorders, 21 (2007): 164175. For a discussion of the history and limitations of the Diagnostic and Statistical Manual, please see: Shadia Kawa and James Giordano, 'A brief historicity of the Diagnostic and Statistical Manual of Mental Disorders: Issues and implications for the future of psychiatric canon and practice', Philosophy, Ethics, and Humanities in Medicine, 7, no. 2 (2012).

3. Andrew Stanway, 'Preface', Oralee Wachter and Dr Andrew Stanway, No More Secrets for Me: Helping to Safeguard Your Child Against Sexual Abuse (London: Penguin Books, 1986), 7; Robin Lenett with Bob Crane, It's OK to Say No!: A Parent/Child Manual for the Protection of Children (2nd edition, London: Thorsons Publishing Group, 1986), 7.

4. Deidre Sanders, The Woman book of love and sex (London: Sphere, 1985).

5. Elizabeth Butler-Sloss, Report of the Inquiry into Child Abuse in Cleveland 1987 (London: Her Majesty's Stationery Office, 1988), 11.

6. Ibid., 11.

7. Ibid., 11.

8. Hilary Freeman, 'When the past won't go away', Independent on Sunday, 8 August 1999, 4; Kidscape Offices, London (hereafter KO), Kidscape Annual Report 1996-7, March 1997, 1; KO, Kidscape Annual Report 1991-2, 'About KIDSCAPE...', March 1992, 3; Michele Elliott, Dealing with Child Abuse: The Kidscape Training Guide (London: Kidscape, 1989), 84; Shy Keenan and Sara Payne, Where Angels Fear: two courageous women bringing hope out of horror (London: Hodder \& Stoughton, 2009), 21. ChildLine discusses receiving calls from adultsboth who were concerned about the welfare of a child but also who were seeking help - in the following annual reports: Bodleian Library (hereafter Bod), P.C06240, ChildLine Annual Reports 1991-1994, Annual Report 1994, 'How ChildLine works', 7; Bod, P.C06240, ChildLine Annual Reports 1991-1994, Annual Report 1993, 'How ChildLine works', 5 .

9. House of Commons, Home Affairs Committee, The Conduct of Investigations into Past Cases of Abuse in Children's Homes, Fourth Report of Session 2001-2, Volume II: Memoranda, 51.

10. Lisa O'Kelly, 'Cries from a nation's troubled psyche', The Observer, 3 October 1993, 25; Janie Lawrence, 'Agony aunts have problems too', Independent, 10 December 1992; Ruth Fisher, 'Agony aunts aid child victims', The Observer, 26 September 1993, 25.

11. Statistic created by examination of Factiva, a database collating over 32,000 newspapers, journals, and newswires. See, for example: Deidre Sanders, 'Dear Deidre: How can I tell husband about sex abuse?', The Sun, 16 May 1999, 31; Deirdre Sanders, 'Bride won't make love: Dear Deidre', The Sun, 15 June 2002, 38; Deidre Sanders, 'Dear Deidre', The Sun, 12 June 2002, 33; Deidre Sanders, 'Dear Deidre', The Sun, 14 January 2001, 43; Deidre Sanders, 'Dear Deidre: Overcoming child 
abuse', The Sun, 31 December 2002, 43; Deidre Sanders, 'Dear Deidre: Abuse agony', The Sun, 7 February 2003, 39; Deidre Sanders, 'Dear Deidre: Hurt by family secret', The Sun, 3 June 2003, 39.

12. 'So hurt by evil abuser', The Sun, 6 December 2006.

13. Deidre Sanders, 'Longing to share my abuse secret', The Sun, 7 November 2006.

14. 'Overcoming child abuse', The Sun, 31 December 2002.

15. O'Kelly, 'Cries from a nation's troubled psyche', 25.

16. Ibid., 25.

17. Virginia Ironside, Problems! Problems! Confessions of an Agony Aunt (London: Robson Books Ltd, 1991), 75-76.

18. Ironside, Problems! Problems!, 87; Lawrence, 'Agony aunts have problems too'. For a later account, see: Deidre Sanders, 'Parents abused sis as well as me', The Sun, 25 June 2007.

19. Lucy Cavendish, 'Agony Aunts interviewed', Lucy Cavendish Counselling, 21 July 2017 <http://www.lucycavendishcounselling.com/2017/07/21/ agony-aunts-interviewed/> (29 January 2018).

20. O'Kelly, 'Cries from a nation's troubled psyche', 25.

21. Ironside, Problems! Problems!, 111.

22. Lawrence, 'Agony aunts have problems too'; O'Kelly, 'Cries from a nation's troubled psyche', 25.

23. Ironside, Problems! Problems!, 108-109; Lawrence, 'Agony aunts have problems too'; O'Kelly, 'Cries from a nation's troubled psyche', 25.

24. Cohen, Family Secrets, 179.

25. Romi Bowen and Angela Hamblin, 'Sexual Abuse of Children', Spare Rib, May 1981, Issue 106.

26. Louise Armstrong, Kiss Daddy Goodnight: A Speak-Out on Incest (New York: Simon \& Schuster, 1978), back cover, 15, 264.

27. Ibid, back cover.

28. See for example: Julie Bindel, 'Louise Armstrong', Guardian, 24 September 2008.

29. Armstrong, Kiss Daddy Goodnight, 65, 67, 68, 69, 70, 116.

30. Ibid., 116.

31. Louise Armstrong, 'Incest: A feminist core issue that needs re-politizising' <http://www.arte-sana.com/articles/incest_feminist_core.htm> (1 May 2018).

32. Victoria Bates, “"Misery Loves Company”: Sexual Trauma, Psychoanalysis and the Market for Misery', Journal of Medical Humanities (2012) 33, $61-81$.

33. Ibid., 62.

34. Dave Pelzer, A Child Called It: One Child's Courage to Survive (Florida: Health Communications Inc., 1995); Dave Pelzer, The Lost Boy: A Foster Child's Search for the Love of a Family (Florida: Health Communications 
Inc., 1997); Dave Pelzer, A Man Named Dave: A Story of Triumph and Forgiveness (New York: Plume, 2000).

35. Dave Pelzer, A Child Called It (London: Orion Books, 2009), 4-7.

36. Ibid., 41.

37. Brendan O'Neill, 'Misery lit ... read on', BBC News, 17 April 2007 <http://news.bbc.co.uk/1/hi/magazine/6563529.stm> (10 March 2014).

38. Reflecting on the reasons behind the declining popularity of misery lit, see: Bates, "Misery Loves Company": 73-74. Contemporary journalists made challenges to-and reflections on-Pelzer's accounts, see, for example: Pat Jordon, 'Dysfunction For Dollars', The New York Times Magazine, 28 July 2002; Geraldine Bedell, 'Child abuse as entertainment', The Observer, 2 September 2001; 'A million-dollar industry called Dave', Independent, 10 February 2004.

39. Anne Rothe, Popular Trauma Culture: Selling the Pain of Others in the Mass Media (New Jersey, New Brunswick, 2011), 93.

40. Jordon, 'Dysfunction For Dollars'; Bedell, 'Child abuse as entertainment', 'A million dollar industry'.

41. See discussion in: Keenan and Payne, Where Angels Fear, 9. See also framing of Pelzer's books on their front covers, in terms of 'courage to survive' and 'triumph and forgiveness'-Pelzer, A Child Called It; Pelzer, The Lost Boy; Pelzer, A Man Named Dave. This framing is consistent across the American and British editions of these books. Contrastingly, for a set of contemporary newspaper accounts written by survivors who emphasised negative emotions and life outcomes, rather than narratives of resilience and survival, see: Madeline Bunting, 'Hush, hush, whisper who dares, 'I used to feel terribly angry with my mother but it's the abuser you should be angry with', Guardian, 22 March 1994, 9.

42. 'Can you get over child abuse?', Daily Mail, 29 April 1998, 59.

43. Jane Cousins Mills, "Putting Ideas into Their Heads": Advising the Young', Feminist Review, 28 (1988), 164.

44. Bedell, 'Child abuse as entertainment'.

45. Ibid.

46. Mary Braid, 'Child abuse inquiry launched: Wide-ranging investigation to shape policy on preventing attacks', The Independent, 10 August 1994; Bodleian Law Library, KN 176.41 INQ 1996, Lord Williams, 'Foreword', National Commission of Inquiry into the Prevention of Child Abuse, Childhood Matters: The Report of the National Commission of Inquiry into the Prevention of Child Abuse. Volume One: The Report, (London: The Stationery Office, 1996), xi.

47. Sarah Boseley, 'Agony aunt on child abuse inquiry', Guardian, 10 August 1994,6 . 
48. National Commission of Inquiry, Childhood Matters, xi-xii.

49. Corinne Wattam and Clare Woodward, “'And Do I Abuse My Children? No!": Learning About Prevention from People Who Have Experienced Child Abuse', Childhood Matters. Volume Two, 50-147.

50. Ibid., 50 .

51. Ibid., 51 .

52. In on online survey advertised and hosted by the BBC between November 2009 and April 2011, 47,869 individuals aged between 18 and 80 reported experiencing child sexual abuse and provided data about life satisfaction. Of these individuals, whose responses were analysed by three psychologists, 83.1 per cent identified as women (Claire F. Whitelock, Michael E. Lamb, and Peter J. Rentfrow, 'Overcoming Trauma: Psychological and Demographic Characteristics of Child Sexual Abuse Survivors in Adulthood', Clinical Psychological Science, 1, no. 4 (2013): 353-355).

Other studies have managed to find equal numbers of male and female participants, for example, this study in American interviewed 64 women and $57 \mathrm{men}$. This gender-balanced sample was recruited through significant canvassing for participants in transport stations, shops, schools, libraries, churches, cafes, and social service agencies (Claire Burke Draucker, Donna S. Martsolf, Cynthia Roller, Gregory Knapik, Ratchneewan Ross, and Andrea Warner Stidham, 'Healing from Childhood Sexual Abuse: A Theoretical Model', Journal of Child Sexual Abuse, 20, no. 4 (2011): $435-466$.

53. Wattam and Woodward, “'And Do I Abuse My Children? No!”, 56-147.

54. Ibid., 74 .

55. Ibid., 115 .

56. Ibid., $75-76$.

57. Ibid., 80-81, 105, 137-139.

58. Ibid., 132-142.

59. Ibid., 132-142.

60. Christine Walby, Matthew Colton, and Maurice Vanstone, 'Victimization, Care and Justice: Reflections on the Experiences of Victims/Survivors Involved in Large-scale Historical Investigations of Child Sexual Abuse in Residential Institutions', British Journal of Social Work, 32 (2002), 546.

61. For an example of a parallel piece of work, looking to collect reflections from survivors, please see: Walby, Colton, and Vanstone, 'Victimization, Care and Justice', 546.

62. National Commission of Inquiry, Childhood Matters, p. 4.

63. Hansard, House of Lords, fifth series, vol. 578, col. 737; Hansard, House of Commons, sixth series, vol. 284, col. 267; Hansard, House of Commons, sixth series, vol. 291, col. 1036; Hansard, House of Lords, 
fifth series, vol. 578, col. 742; David Brindle, 'Child abuse inquiry urges cabinet minister for children', Guardian, 22 October 1996, 10; Louise Jury, 'Child abuse inquiry launched by NSPCC', Guardian, 24 March 1994, 7; David Brindle, 'Public urged to act as abuse 'harms 1 million children a year"', Guardian, 23 October 1996, 2; C. J. Hobbs and P. L. Heywood, 'Doctors have a vital role in identifying children at risk of abuse', British Medical Journal, 1 March 1997, 314.

64. National Commission of Inquiry, Childhood Matters, 5-6.

65. Niall Dickson, 'For crying out loud: overleaf we outline new ways of helping parents and children', Guardian, 23 October 1996, 2-3.

66. Ibid., 547.

67. Ibid., 547.

68. Ibid., 547.

69. Home Affairs Committee, The Conduct of Investigations into Past Cases of Abuse, 50.

70. Ibid.

71. The sociologist Nancy Whittier has described the 'survivor movement' in America in The Politics of Child Sexual Abuse: Emotions, Social Movements and the State (Oxford: Oxford University Press, 2009). Her book is based on 40 interviews with activists from feminist and survivor groups, as well as 'counter-mobilisations' such as false memory groups. Groups which emerged in the American context include the Rape, Abuse and Incest National Network, established in 1994, Pandora's Project, established in 1999, and the National Association of Adult Survivors of Child Abuse, established in 2001. In Australia new groups included Adults Surviving Child Abuse, founded in 1995, and in Europe, Survivors Voice Europe, focused on abuse by the clergy, and isurvive, an online self-help community.

72. The Survivors Trust, 'About TST' < http://www.thesurvivorstrust.org/ about-tst/> (22 April 2015).

73. 'CIS'ters-surviving rape \& sexual abuse' <http://www.cisters.org.uk/> (6 May 2015); 'Male Survivors Trust' <http://malesurvivorstrust.org. $\mathrm{uk} />(6$ May 2015).

74. Keenan and Payne, Where Angels Fear, 27.

75. Sharon Hendry, We're the pervs' enemy ... we will make THEIR lives a misery', The Sun, 10 April 2006.

76. Keenan and Payne, Where Angels Fear.

77. Heather Kirby, 'I was a child sex abuse victim', The Times, 22 November 1996, 16; Sophie Goodchild, 'Paedophilia in Britain: the victim's story', Independent on Sunday, 24 June 2007, 17.

78. Kirby, 'I was a child sex abuse victim', 16; Freeman, 'When the past won't go away', 4. 
79. Kirby, 'I was a child sex abuse victim', 16.

80. Home Affairs Committee, The Conduct of Investigations into Past Cases of Abuse.

81. Keenan and Payne, Where Angels Fear, 25-6.

82. See for example: Freeman, 'When the past won't go away', 4.

83. Joanna Bourke, The Story of Pain: From Prayer to Painkillers (Oxford: Oxford University Press, 2014), 52.

84. See, for example, the variety of emotions within the artwork and poetry on the One in Four website, <http://www.oneinfour.org.uk/survivorsvoices-uk/> (10 May 2018).

85. Companies House, National Association for People Abused in Childhood, Financial statements.

86. Alex Mold, 'Patient Groups and the Construction of the PatientConsumer in Britain: An Historical Overview', Journal of Social Policy, 39 (2010): 509-528; Alex Mold and Virginia Berridge, Voluntary Action and Illegal Drugs: Health and Society in Britain since the 1960s (Basingstoke: Palgrave Macmillan, 2010), 22, 147; Crossley and Crossley, '“Patient' voices, social movements and the habitus': 1488.

87. Brief summaries of these measures and more are outlined in: 'The Government Policy Context', Catherine Itzin, Tackling the Health and Mental Health Effects of Domestic and Sexual Violence and Abuse (London: Department of Health, 2006), 19-29.

88. Ibid., 20.

89. See for example: Home Affairs Committee, The Conduct of Investigations into Past Cases of Abuse, 47-55.

90. Itzin, Tackling the Health and Mental Health Effects of Domestic and Sexual Violence and Abuse, 3, 4, 5, 7.

91. Ibid., 5 .

92. Ibid., 60-61.

93. Ibid., 60-61.

94. Ibid., 60-61.

95. A Delphi Method consultation provides questionnaires to experts in a series of rounds (the Victims of Violence and Abuse Prevention Programme used three). The questionnaire responses are anonymised, and an analyst summarises the data found after each round and distributes this summary to all participants, with the hope that the experts will consider alternative viewpoints in the subsequent rounds and that the group will find a common answer. Catherine Itzin, Susan Bailey, and Arnon Bentovim, 'The effects of domestic violence and sexual abuse on mental health, The Psychiatric Bulletin, 32 (2008): 448-450. 
96. Catherine Itzin, Ann Taket and Sarah Barter-Godfrey, Domestic and sexual violence and abuse: tackling the health and mental bealth effects (London: Routledge, 2010), 189-190.

97. Catherine Itzin, Ann Taket, and Sarah Barter-Godfrey, Domestic and Sexual Violence and Abuse: Findings from a Delphi expert consultation on Therapeutic and Treatment Interventions with Victims, Survivors and Abusers, Children, Adolescents, and Adults (Melbourne, Australia: Deakin University, 2010), vii.

98. Itzin, Taket and Barter-Godfrey, Domestic and Sexual Violence and Abuse: Tackling the Health and Mental Health Effects, 189-190.

99. Ibid., 189.

100. Itzin, Taket, and Barter-Godfrey, Findings from a Delphi expert consultation, $\mathrm{v}, 63-70$.

101. Ibid., iv, v, 63-70.

102. Ibid., 95 .

103. Ibid., 95.

104. Itzin, Taket and Barter-Godfrey, Domestic and Sexual Violence and Abuse: Tackling the Health and Mental Health Effects, 14.

105. Ibid., 1 .

106. Itzin, Tackling the Health and Mental Health Effects of Domestic and Sexual Violence and Abuse, 1, 5, 13, 42.

107. Ibid., 11.

108. These limitations are echoed in concurrent literature about how patients have been involved in health policy reform. See, for example: Crossley and Crossley, 'Patient' voices, social movements and the habitus': 14771489; Mold, 'Patient Groups and the Construction of the PatientConsumer in Britain': 505-521.

109. Sara Payne, Redefining justice: Addressing the needs of victims and witnesses (London: Ministry of Justice, 2009), 5; Sandra Walklate, 'Courting Compassion: Victims, Policy, and the Question of Justice', The Howard Journal of Criminal Justice, 51 (2012): 109-121.

110. See, for example, the significance of using funds to improve statutory provisions for victims as documented in: Cross Government Action Plan on Sexual Violence and Abuse (London: Her Majesty's Stationery Office, 2007), 23-24.

111. 'NAPAC's Peter Saunders on “Big” Charities', The Needle, 24 October 2013 <https://theneedleblog.wordpress.com/2013/10/24/napacspeter-saunders-on-big-charities/> (4 May 2015). For an academic analysis of the Jimmy Saville case, see: Chris Greer and Eugene McLaughin, 'The Sir Jimmy Savile scandal: Child sexual abuse and institutional denial at the BBC' Crime, Media, and Culture 9 (2013): 247-248, 252. 
112. Joe Murphy and Humfrey Hunter, 'Attack by children's charities steps up the pressure on Hodge', The Evening Standard, 4 July 2003, 6; Peter Saunders, 'Letters to the editor', The Times, 23 September 2003; Matthew Norman, 'With a past like hers, Margaret needs a bit more humility', Independent, 10 March 2015; 'Rights of children and workers-DebateThe Register-Letter', The Times, 14 October 2002, 17; Geoffrey Lakeman, 'Paedo gets $£ 5,500$ for "stress', Daily Mirror, 3 March 2005, 1,4 .

113. 'Rights of children and workers', 17.

114. Murphy and Hunter, 'Attack by children's charities steps up the pressure on Hodge', 6; Saunders, 'Letters to the editor'; Matthew Norman, 'With a past like hers, Margaret needs a bit more humility', Independent, 10 March 2015 <http://www.independent.co.uk/voices/comment/witha-past-like-hers-margaret-hodge-might-show-a-bit-more-humility-10098871.html> (15 June 2015).

115. Nick Speed, 'Hodge's care home blunders may have 'let in' paedophiles', The Sunday Times, 6 July 2003, 6.

116. Geoffrey Lakeman, 'Paedo gets $£ 5,500$ for “stress', Daily Mirror, 3 March 2005, 1, 4; James Slack, 'Human rights fiasco', Daily Express, 2 March 2005, 33; Chris Brooke, 'Euro Judges take pity on the paedophile who found it stressful waiting to face trial $\ldots$ and award him $£ 6,000$ ', Daily Mail, 2 March 2005, 6.

117. Testimony from Worrall Thompson is at: 'Chef backs help for abuse victims', Coventry Evening Telegraph, 15 September 2003, 19; Emma Maier, 'Celebrity chef makers plea for child abuse helpline for adults', Third Sector, 17 September 2003, 1. Testimony from Hall is at: Alexa Baracaia, 'My tormet at hands of father, by Jerry Hall', London Evening Standard, 10 May 2006, 1; 'Jerry's agony', The Sun, 11 May 2006; 'Jerry: My abuse hell', The Express, 11 May 2006, 6.

118. Coverage is Ibid. Analysis from Third Sector is at: Penelope Gibbs, 'Communications-Press Celebrities can't do everything', Third Sector, 23 May 2007, 23.

119. Keenan, Broken, 255-269.

120. Clare Dwyer Hogg, 'To catch a child molester', Independent on Sunday, 10 February 2008, 47.

121. Louise Carpenter, 'I will survive', The Observer, 10 February 2008.

122. 'Wonder Woman: Shy Keenan', 6 September 2010 <http://www.youtube.com/watch? v=D4rEwituBus> (10 March 2014).

123. A Family Affair', Newsnight. Keenan further emphasised this critical position in subsequent newspaper coverage, telling the Independent in 2008 that when she was nine, she had told a social worker that her stepfather was sexually assaulting her on a regular basis. After talking to him, the 
social worker wrote that Shy had forced herself upon him on her notes. This short statement, Keenan felt, 'influenced everyone else in authority I tried to tell.' (see Dwyer Hogg, 'To catch a child molester', 47).

124. Hendry, We're the pervs' enemy'.

125. 'A Family Affair', Newsnight.

126. Carpenter, 'I will survive'.

127. Description of programme and full transcript available at: Sarah Macdonald, 'Suing the Pope - Colm's story', BBC News, 29 January 2003.

128. Full transcript available at: Sarah Macdonald, 'Suing the Pope - Colm's story', BBC News, 29 January 2003.

129. Full transcript available at: Sarah Macdonald, 'Suing the Pope - Colm's story', BBC News, 29 January 2003.

130. 'Pope admits church lacked vigilance', Al Jazeera English, 16 September 2010, 2; 'Abuse victims call for Pope apology', Daily Star, 16 September 2010,1 .

131. Full transcript available at: Sarah Macdonald, 'Suing the Pope - Colm's story', BBC News, 29 January 2003.

132. Ibid.

133. 'Adver Comment ... Listen to those who know', Swindon Advertiser, 14 June 2007.

134. Ibid.

135. Home Affairs Committee, The Conduct of Investigations into Past Cases of Abuse, 52.

136. Nadia Khomami, 'Theresa May scraps panel for inquiry into child sex abuse, report says', Guardian, 21 December 2014 <http://www.theguardian.com/global/2014/dec/21/theresa-may-child-sex-abuseinquiry-panel-scrapped> (16 May 2015).

137. Wattam and Woodward, 'And Do I Abuse My Children? No!', 1.

138. Home Affairs Committee, The Conduct of Investigations into Past Cases of Abuse, 51 .

139. Williams, 'Foreword', Childhood Matters. Volume Two, p. vii; Meg Munn, 'Foreword', Child Protection All Party Parliamentary Group: Seminar Series of Child Sexual Abuse (London: Child Protection All Party Parliamentary Group, 2014), 3.

140. See, for example: One in Four, Survivors' Voices: Breaking the silence on living with the impact of child sexual abuse in the family environment (One in Four, November 2015).

141. Pennies versus Pounds, Community Care, 11 April 2007.

142. Armstrong, Kiss Daddy Goodnight, 116. 
143. For a fascinating account of the emergence of one particular new category, autism, see: Bonnie Evans, The metamorphosis of autism: A history of child development in Britain (Manchester: Manchester University Press, 2017). In terms of the history of post-war education, see: David Crook, 'Local Authorities and Comprehensivisation in England and Wales, 1944-1974', Oxford Review of Education, 28, no. 2-3 (2002): 247-260; David Crook, 'Politics, politicians and English comprehensive schools', Journal of the History of Education Society, 42, no. 3 (2013): 365-380; A. H. Halsey, Education, economy, and society: a reader in the sociology of education (New York: Free Press; London: Collier-Macmillan, 1965); Richard Harris and Samuel Rose, 'Who benefits from grammar schools? A case study of Buckinghamshire, England', Oxford Review of Education, 39, no. 2 (2013): 151-171; Terry Haydn, 'The strange death of the comprehensive school in England and Wales, 1965-2002', Research Papers in Education, 19, no. 4 (2004): 415-432. For an account of 'staging and aging' in the early twentieth century, see: Clementine Beauvais, 'Ages and ages: the multiplication of children's 'ages' in early twentieth-century child psychology', History of Education, 45, no. 3 (2015): 304-318.

Open Access This chapter is licensed under the terms of the Creative Commons Attribution 4.0 International License (http://creativecommons.org/licenses/ by $/ 4.0 /)$, which permits use, sharing, adaptation, distribution and reproduction in any medium or format, as long as you give appropriate credit to the original author(s) and the source, provide a link to the Creative Commons license and indicate if changes were made.

The images or other third party material in this chapter are included in the chapter's Creative Commons license, unless indicated otherwise in a credit line to the material. If material is not included in the chapter's Creative Commons license and your intended use is not permitted by statutory regulation or exceeds the permitted use, you will need to obtain permission directly from the copyright holder.

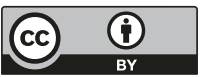

